\title{
Tsunami Preparedness: Is Zero Casualties Possible?
}

\author{
EdDIE N. BeRnARD ${ }^{1}$
}

\begin{abstract}
Inspired by the goal of Kuroshio Town, a coastal community in southern Japan, to have zero casualties from the next tsunami, this study will focus on a tsunami preparedness program to save everyone's life. The first step in the program is to determine how many people in a tsunami hazard zone can be protected using existing horizontal and vertical evacuation procedures and shelters. The people who live or work in tsunami hazard zones but cannot or will not use these shelters are identified as "unprotected". A possible solution to save the "unprotected" is to offer a shelter-inplace option to complement the horizontal and vertical evacuation options. Such a shelter-in-place option would provide protection for those unable or unwilling to use horizontal or vertical evacuation facilities. The shelter-in-place option would offer customized protection for individuals and businesses free of contagious diseases found in gatherings associated with horizontal or vertical evacuation shelters. To be effective, the shelter-in-place option must be immediately accessible to protect people from drowning, being crushed, being hit by floating objects, suffocation by ingesting silt laden water, fires, and hypothermia. An example of a shelter-in-place product is a patented, spherical aluminum capsule that floats on the tsunami protecting people from fire, cold water, being crushed, ingesting contaminated water, being hit by floating objects, and drowning. Since the capsule floats, there is no need to accurately predict tsunami flooding heights. This study includes numerical model simulations for 20 capsules subjected to 3 tsunami flooding scenarios in Newport, Oregon indicating the capsules have a low probability of being washed out to sea. Using a shelter-inplace option, along with horizontal and vertical evacuation options, zero casualties from the next tsunami is possible.
\end{abstract}

Keywords: Tsunami preparedness, Shelter-in-place, Tsunami vertical evacuation, Tsunami horizontal evacuation.

\section{Introduction: the Problem}

Tsunamis kill people. Davies et al. (2017) conducted a probability study for the global tsunami

Supplementary Information The online version contains supplementary material available at https://doi.org/10.1007/s00024022-02948-7.

1 Survival Capsule, LLC, Mukilteo, WA, USA. E-mail: eddie.bernard@comcast.net hazard and reported on exceedance flooding as illustrated in Fig. 1. Most coastlines of the world have a tsunami hazard. An estimated 600 million people live and work within $10 \mathrm{~m}$ of sea level (Merkens et al., 2016). This estimate means that hundreds of millions of people in the world are exposed to tsunami flooding risk. Past history of tsunami casualties indicates that the best prepared nation in the world, Japan, can expect about 3\% of the people who live and work in the tsunami hazard zone to die (Koshimura and Shuto, 2015). In contrast, an unprepared nation, like the Aceh Province of Indonesia, lost about $25 \%$ of the population $(168,560$ dead or missing) living within $20 \mathrm{~m}$ of sea level during the 2004 Indian Ocean tsunami (Frankenberg et al., 2011). Indonesia had no tsunami hazard maps to estimate the population at risk, so the population in nine districts of Aceh Province living within $20 \mathrm{~m}$ of sea level was chosen as a proxy for the population at risk (Doocy et al., 2007). With these two extreme references, we can estimate that between 3 and $25 \%$ of the people who live or work in tsunami hazard zones will die during the next tsunami. Unprepared tsunami populations had over 8 times $(8 x)$ the casualties as the prepared populations!

Following the 2011 Japanese tsunami, medical examiners documented the cause of death for the approximately 19,000 victims. This was the first time that tsunami forensics were studied and reported (Seto et al., 2019). One key finding was that for every person who was injured, three people died (Ochi et al., 2013). In other words, tsunamis are a killer hazard. In most natural hazards, there are many injuries but fewer casualties. For tsunamis, the opposite is true. People who are engulfed by the tsunami during flooding have little chance of survival. 


\section{1/500 exceedance rate run-up height}

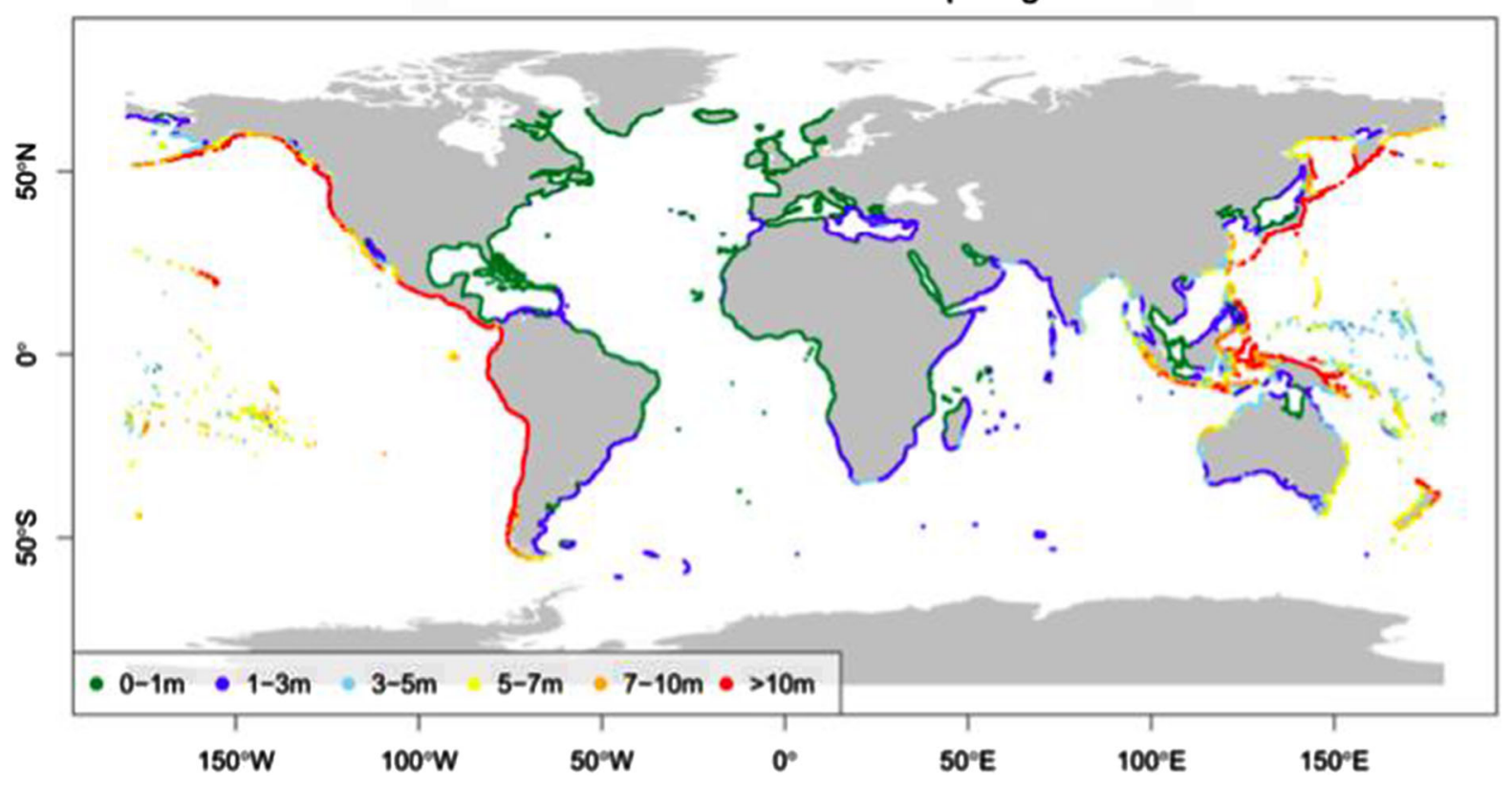

Figure 1

Probabilistic global tsunami risks for 500 year recurrence rate (Davies et al., 2017)

Japanese medical examiners and other experts reported that about $93 \%$ of deaths were attributable to drowning, people hit by floating objects, hypothermia and a surprising number swallowed dirty contaminated water that contained sediments and toxic fluids. The sand, sediments and toxic fluids turned the color of the water black giving rise to the term black tsunami (Fig. 2). Victims suffocated from sand/sediment in their lungs. About $4 \%$ were crushed and about $1 \%$ were burned to death (Seto et al., 2019). Among survivors, during the following decade, hundreds died from tsunami related respiratory illnesses termed "tsunami lung" (Inoue et al., 2012). This is a respiratory problem that's created when survivors ingest sand or contaminated fluids or are exposed to other infected people in shelters (Suzuki et al., 2011). They survived the tsunami, but their respiratory problems continued long after the tsunami event.

Past studies of tsunami preparedness have focused only on horizontal and vertical evacuations in the U.S. (Wood et al., 2014), Chile (Álvarez et al., 2018), Australia (Osso \& Dominey-Howes, 2010), Indonesia (Birkmann et al., 2008), Japan (Mas et al., 2015). This

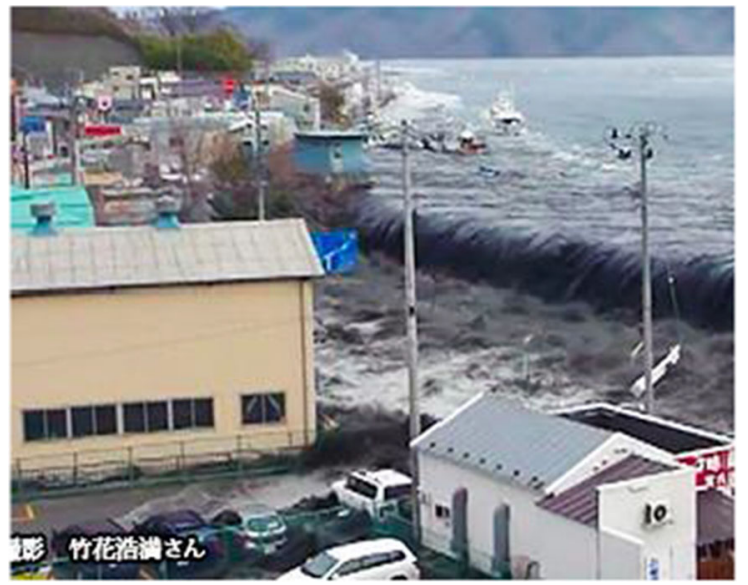

Figure 2

Sand, sediment and toxic fluids mix with the tsunami turning the flooding waters black in Miyako City, overtopping seawalls and flooding streets in Iwate Prefecture, Japan, after the magnitude 9.0 earthquake struck the area March 11, 2011. Credit: Mainichi Shimbun/Reuters

is the first study to introduce a shelter-in-place option for saving lives during a tsunami. 
2. Horizontal and Vertical Evacuation Case Studies: Kuroshio Town, Japan and Ocean Shores, United States

The town of Kuroshio Town Japan is aiming to have zero victims from the next tsunami. A tsunami hazard map (Fig. 3) has been prepared for Kuroshio Town based a Nankai Trough earthquake and tsunami (CDMC, 2012; Kitagawa, 2019). This community could be flooded within $8 \mathrm{~min}$ after the earthquake with tsunami run-up flooding up to $34 \mathrm{~m}$ and an atrisk population of 4600 people (Information and Disaster Prevention Department of Kuroshio-cho).

Because Kuroshio Town government knows that people who are engulfed by the tsunami during flooding have little chance of survival, their plan uses two options for evacuating 4600 people from the tsunami hazard zone. The first option is horizontal evacuation (Fig. 4). Evacuation takes place on foot, bicycle or vehicle. People gather in communal
Problems with Horizontal Evacuation to Shelters

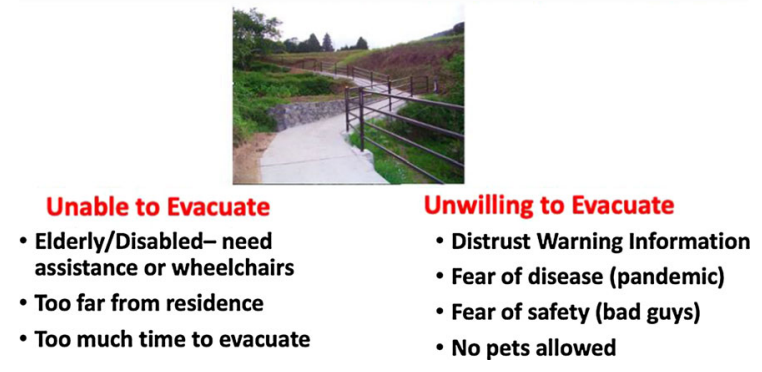

Figure 4

Problems with horizontal evacuations. Photo from Information and Disaster Prevention Department of Kuroshio Town

shelters to wait out the tsunami. However, there are problems with people unable to evacuate horizontally including the time it takes to evacuate and the ability of people to evacuate quickly due to disabilities or age. There is also the issue of people unwilling to evacuate because they don't want to gather in shelters due to fear of disease or safety (Suzuki et al., 2011).

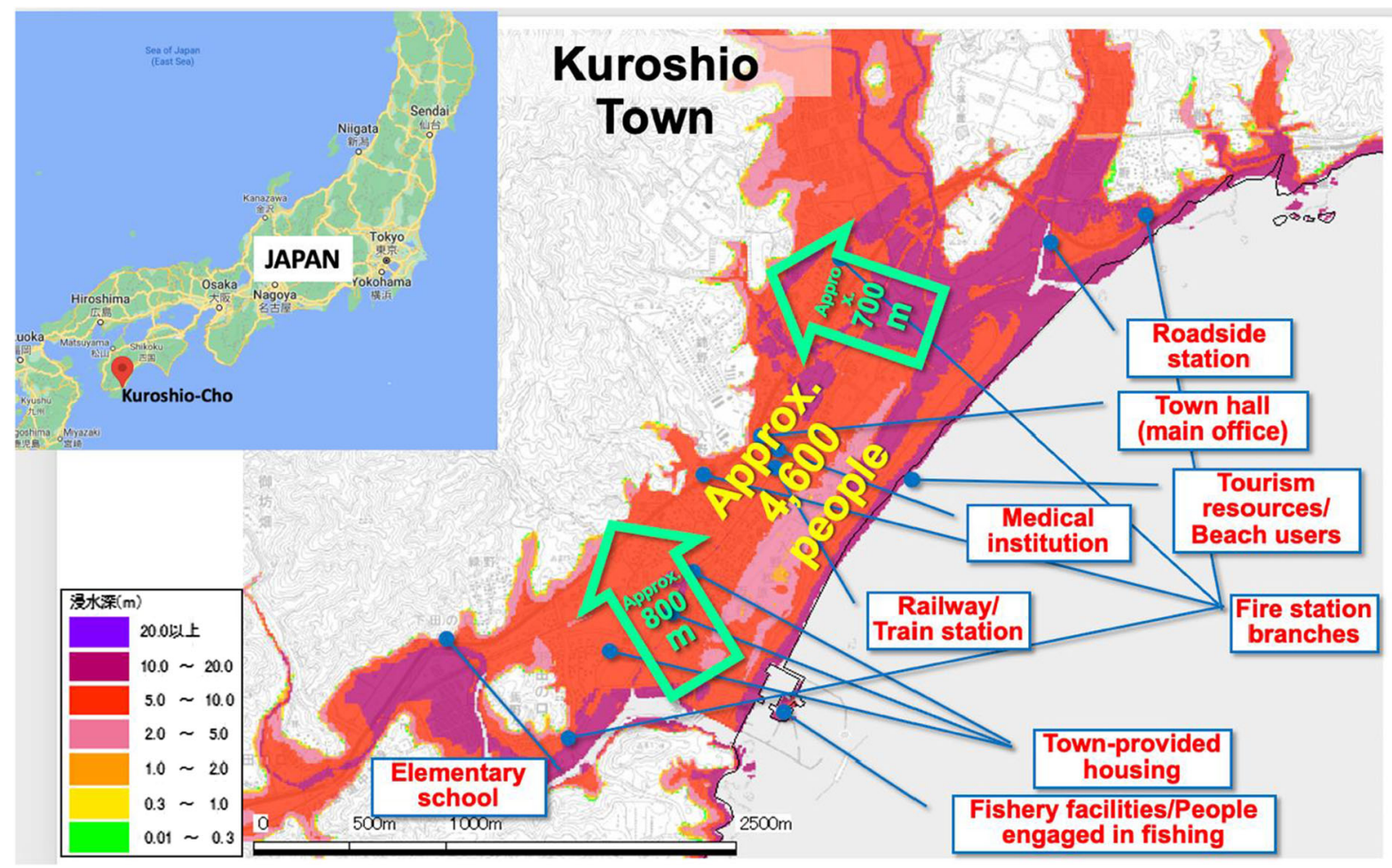

Figure 3

Kuroshio Town tsunami hazard map based on Nankai Trough earthquake and tsunami simulation. (Information and Disaster Prevention Department of Kuroshio-cho) 
Also, they may not trust the warning information or may have pets they do not want to abandon. Probably the most common reason for people to avoid evacuations is their distrust of tsunami information. For example, during the 2011 Japanese tsunami the Japanese Meteorological Agency (JMA) issued tsunami warnings about $3 \mathrm{~min}$ after the earthquake started shaking (Cyranoski, 2011) that predicted a $3 \mathrm{~m}$ tsunami. Since it was a cold snowy day, many residents thought they were protected from a $3 \mathrm{~m}$ tsunami by seawalls, so they decided NOT to evacuate. Unfortunately, the earthquake continued to shake for over 6 min causing JMA to issue a second warning $20 \mathrm{~min}$ later for a $10 \mathrm{~m}$ tsunami (Cyranoski, 2011). The second warning was not received by many communities due to disruptions in communications from the earthquake and tsunami. Other reasons people may be unwilling to evacuate include safety. Two safety issues are (1) bad people in the shelters who might harm evacuees and (2) contagious diseases spread within crowded shelters (Suzuki et al., 2011). During the pandemic, guidelines were issued by the Intergovernmental Oceanographic Commission "There is general acceptance that the life-saving response to an imminent natural hazard should take priority over mitigation measures instated during a pandemic." (IOC, 2021). Individuals may not agree with these guidelines. Another reason people are unwilling to evacuate is that pets are generally not allowed in the shelters. Animal lovers are hesitant to leave their pets. Unwillingness to evacuate has been reported following other tsunamis. The most common reason is fear of losing their personal or business property to looters. Unwillingness to evacuate is a real problem that can lead to more tsunami deaths.

Their second option is vertical evacuation (Fig. 5) where about 300-500 evacuees climb a 3-5 story tsunami structure to escape tsunami flooding and death. However, there are problems with people unable to evacuate vertically, including the time it takes to evacuate and the ability of people to evacuate and climb 3-5 flights of stairs quickly due to disabilities or age. There is also the issue of people unwilling to evacuate because they don't want to gather in the structure due to fear of building failure (McCaughey et al., 2017), personal safety, disease, overcapacity or

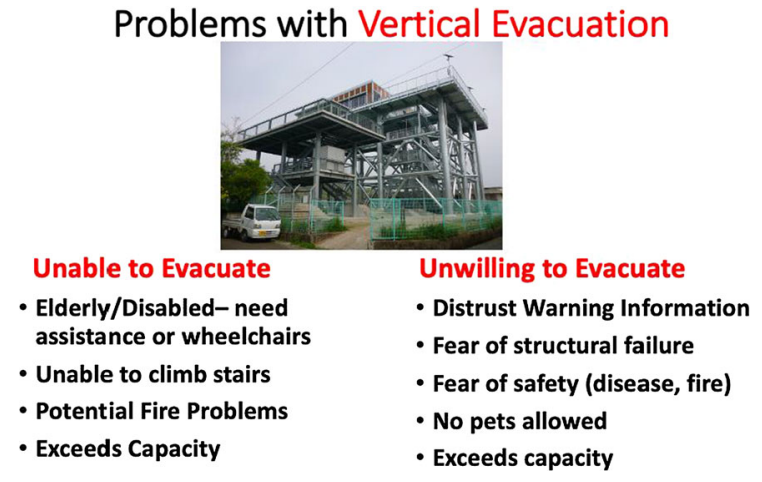

Figure 5

Problems with vertical evacuations. Photo from Information and Disaster Prevention Department of Kuroshio-cho

fires (Fraser et al., 2012). They may also not trust the warning information or may have pets they do not want to leave behind.

Vertical evacuations structures pose a different type of risk than horizontal evacuations. The vertical evacuation structures are designed and built to hold a fixed number of people. Since a tsunami can occur at any time, it is not possible to predict precisely how many people will arrive at the structure during an evacuation. If the structure reaches capacity and people are still evacuating, how will the decision be made to reject evacuees? If the evacuees are allowed to exceed capacity, there is a danger that the structure will fail, and all people will be subjected to injury or death. An example of the overcapacity problem exists for the coastal community of Ocean Shores, Washington that has a tsunami evacuation map shown in Fig. 6. Ocean Shores is a peninsula about $13 \mathrm{~km}$ ( 8 miles) long and $3 \mathrm{~km}$ ( 2 miles) wide that has a population of over 12,000 . It also is a favorite tourist destination, so the at-risk population can expand during peak travel times. As shown in Fig. 6 tsunami evacuation map, the entire peninsula is projected to be flooded by over $10 \mathrm{~m}$ (33 feet) tsunami height generated by a Cascadia Subduction Zone earthquake. Freitag and Gomez, (2021) determined that only $8.3 \%$ of the population (1014 out of 12,192) can evacuate to high ground within $15 \mathrm{~min}$.

In December 2020, the Ocean Shores city council approved the construction of a vertical evacuation structure with a capacity to protect 800 people near the center of the peninsula (Ocean Shores City 


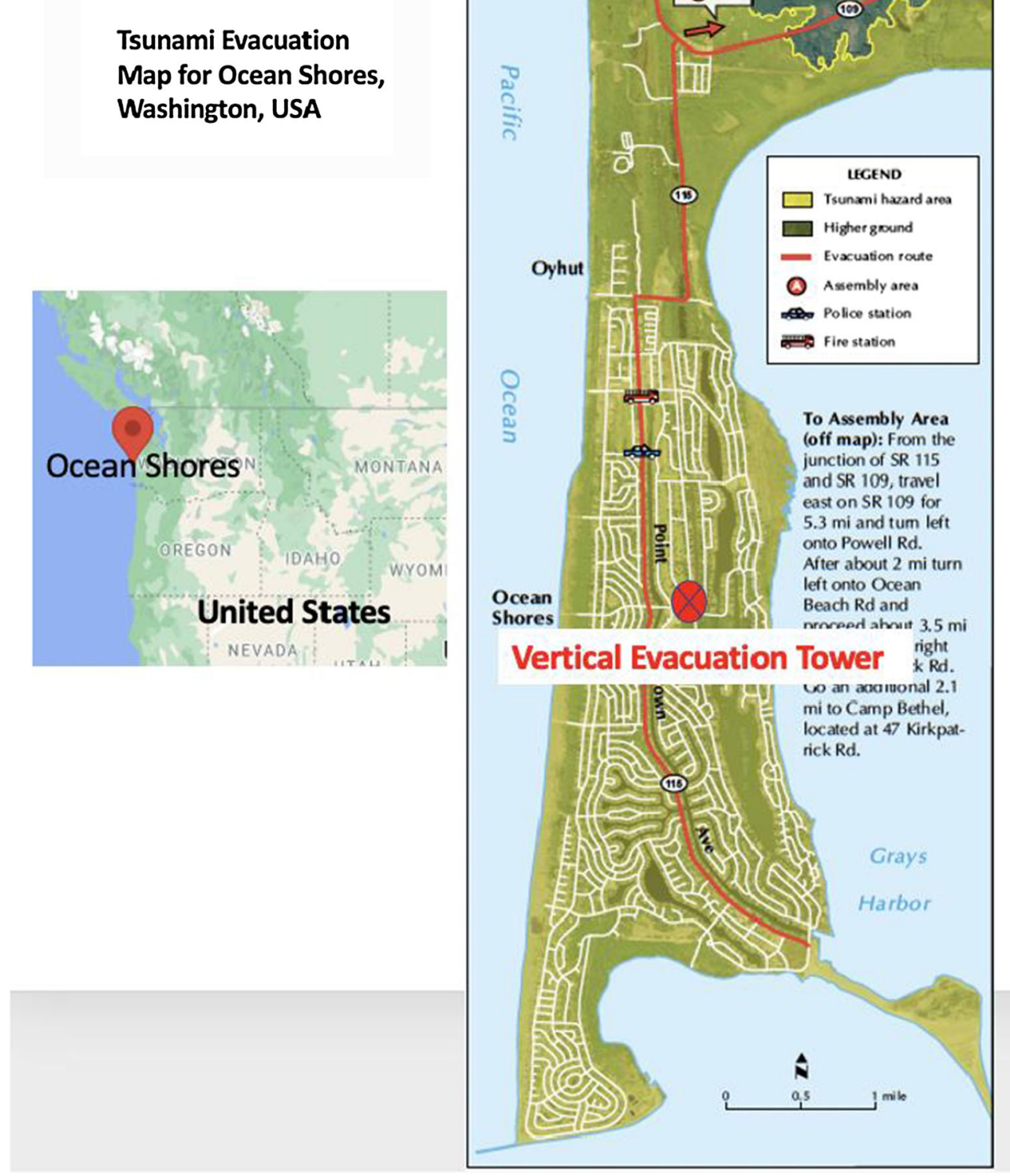

Figure 6

Tsunami evacuation map for Ocean Shores, Washington, a coastal community with a residential population of about 12,000 people. (Washington State Division of Natural Resources, Freitag and Gomez (2021)). The location of the 800-person vertical evacuation structure, presently being considered for construction, is shown by the red oval

Council Meeting minutes). The site of the vertical evacuation structure is shown in Fig. 6. Local residents have expressed concerns that the structure will create problems as over 12,000 people vie for 800 positions on the structure (personal communication with Susan Conniry, Ocean Shores City Council member) during the next tsunami. Overcapacity is a real physical and social issue that needs to be considered when planning tsunami mitigation procedures.

Another issue affecting the use of vertical evacuation structures is cultural. One study of a 2016 
earthquake/tsunami evacuation in Sukan, Sumatra, Indonesia found that no one used the tsunami vertical structure. The structure had been constructed following the 2004 Indian Ocean tsunami. Many believed the structure would fail, so people evacuated horizontally toward inland destinations, especially to mosques (McCaughey et al., 2017). This vividly illustrates that engineering solutions can be rendered less effective if they are out of step with the social/cultural norms (Hewitt, 1983). To make disaster-mitigation projects as effective as possible, it is necessary to conduct social studies to determine cultural as well as engineering aspects of mitigation options.

Emergency managers in Kuroshio Town carefully examined horizontal and vertical evacuation effectiveness through an extensive community participation effort to identify evacuation problems. They held multiple drills that involved the public to identify barriers to effective evacuations. They then upgraded horizontal evacuation routes by installing concrete walkways, steps and railing to assist evacuees. They erected vertical evacuation structures in strategic locations to provide quick escape from the tsunami. After the horizonal evacuation upgrades and vertical structures were installed, they conducted additional drills to determine the numbers of unprotected people. Their analysis is summarized in Fig. 7 where they identified 153 (3\%) people who could not evacuate even with help. They also identified 753 $(16 \%)$ people who will need assistance in evacuation. The Kuroshio Town example illustrates the limits of horizontal and vertical evacuations (between 3-16\%

\section{Kuroshio Town Analysis of People Unable to Evacuate}

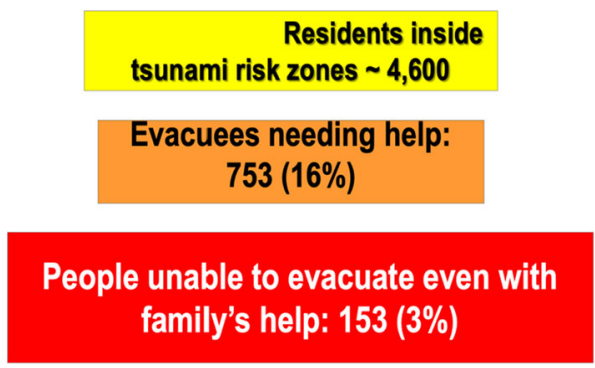

Figure 7

Kuroshio-cho identification of people unable to evacuate. (Information and Disaster Prevention Department of Kuroshio-cho) unprotected) because they are unable to evacuate during the next tsunami. For Ocean Shores, Washington, the situation is much worse. In this case, after constructing an 800-person vertical evacuation structure, $85 \%$ of Ocean Shores population is unprotected. These analyses assumed that all residents would be willing to evacuate. The numbers unwilling to evacuate remain unknown. However, an unwillingness to evacuate indicates that more options are needed to have zero casualties from the next tsunami.

\section{Shelter-in-Place Option}

A possible third option for those who are unable or unwilling to evacuate is a shelter-in-place option where an appropriate shelter is immediately available to people who live or work in a tsunami hazard area. For the tsunami hazard, a suitable shelter must be located at a residence or business so that evacuation can take place within one minute. As discovered from forensics of the 2011 tsunami, the shelter must protect occupants from drowning, being crushed by floating objects, being burned to death, being exposed to cold water, ingesting toxic sand and silt and exposure to contagious diseases (Fig. 8).

Survival Capsule, an aerospace company in Seattle, Washington has designed, built, tested, and patented (US 8,689,495) a shelter-in-place structure specifically for the tsunami hazard. The capsule was designed, analyzed and tested using aerospace engineering technology that is watertight and floats to protect from drowning, being crushed, being hit by

\author{
Possible Third Option: \\ Shelter-in-Place \\ - Immediate access - evacuation time is less than a minute. \\ Shelter is located at residence or business
}

\section{Must protect occupants from}

- Drowning

- Being hit or crushed by floating objects

- Being burned by fires

- Hypothermia (exposure to cold water)

- Swallowing toxic dirt mixed in tsunami water

- Contagious diseases

Figure 8

Requirements for a tsunami shelter-in-place structure 
floating objects or ingesting toxic sand (Sharpe et al., 2013). The structure is covered with aircraft grade aluminum offering protection from being crushed, punctured or fires. This is the same type of aluminum used on commercial aircraft. The properties of this aluminum are well known because it is used extensively in aircraft traveling at $800 \mathrm{~km} / \mathrm{h}(500 \mathrm{mph})$. There is ample evidence that this structure will protect people from a tsunami with velocities of $40 \mathrm{~km} / \mathrm{h}$ (25 mph). The design has occupants seated at the bottom of the sphere creating a low center of gravity (see https://www.youtube.com/watch?v=wSF7MSv $87 \mathrm{Ko}$ ). The low center of gravity prevents the capsule from overturning. The capsule is insulated providing protection from cold water or fires (Fig. 9a). It has air vents that supply air that can be closed in the event the capsule is submerged. Oxygen tanks may be installed to supply air if the capsule is submerged. One of the reasons people die in the tsunami is that they attempt to return to their homes to gather valuables or pets. The capsule has storage for valuables, as well as personal items, important documents, first aid kits, medications, food, water and pets (Fig. 9). GPS transmitters can be added to the capsule to track the location of the capsule for rescue and recovery. Finally, the capsule provides a temporary shelter once the tsunami subsides protecting the occupants from exposure to the weather and contagious diseases possibly found in crowded shelters (Suzuki et al., 2011). A lesson learned from the 2011 Japanese tsunami is that the sludge, deposited during the tsunami recession, can cause contagious respiratory diseases. To avoid this problem, it is recommended that the capsule contain sturdy waterproof boots and $\mathrm{N} 95$ facemasks for each occupant.

The capsule was designed using aerospace engineering technology, including numerical models for simulating capsule performance subjected to tsunami like forces (Sharpe et al., 2013). The capsule design led to the construction of a prototype capsule that was tested under laboratory conditions to compare simulations with the prototype capsule for puncture resistance, loads, fire and water tightness (Fig. 10).

a. Puncture Resistance: one hazard discovered in the 2011 tsunami was that floating objects were punctured by rebar used in construction to secure buildings to their foundations. This construction practice is used extensively in the world in earthquake building codes to keep the structures from vibrating off their foundations. The problem during a tsunami is that the house/structure is washed away leaving the foundation and exposed rebar (Fig. 11).

b. Load: many people were crushed to death in the 2011 tsunami requiring that the capsule protect
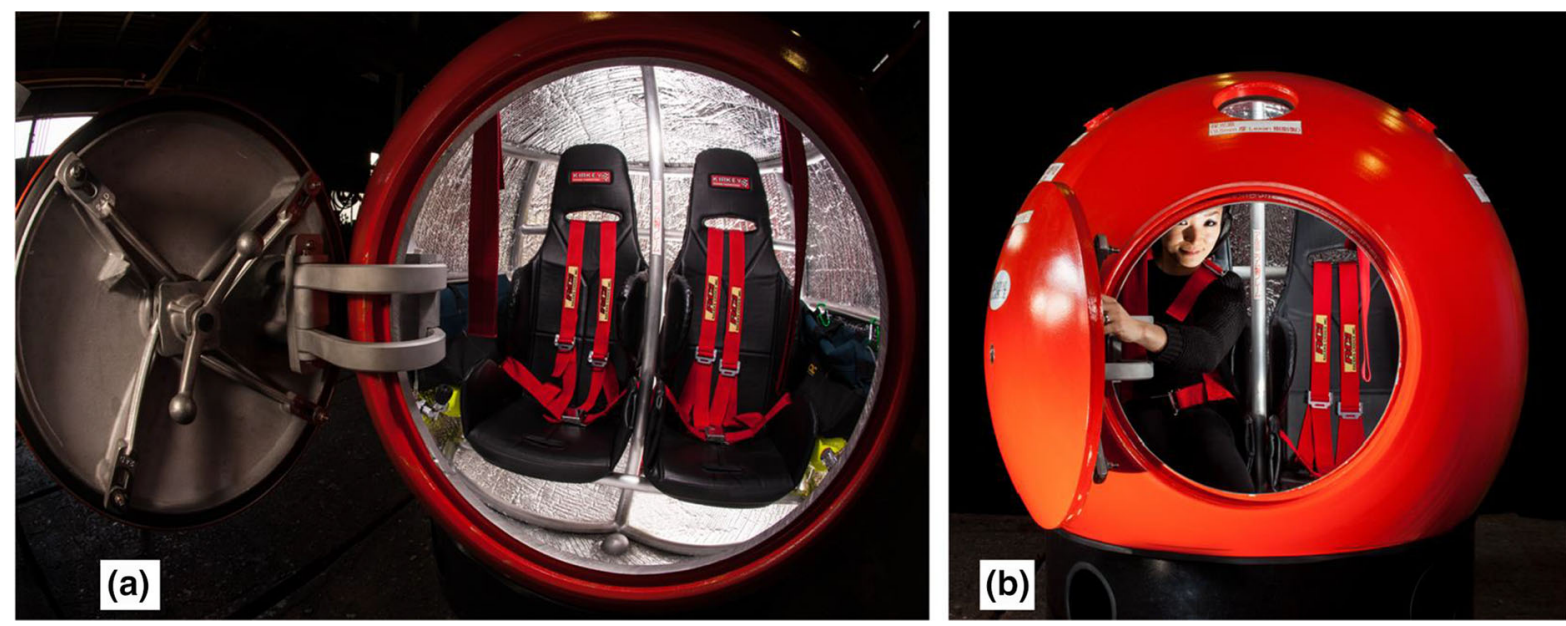

Figure 9

a 2-person survival capsule showing interior with insulation and 5-point harness/seatbelt for each seat (b) 2-person capsule with and a single occupant. Photos by Survival Capsule 

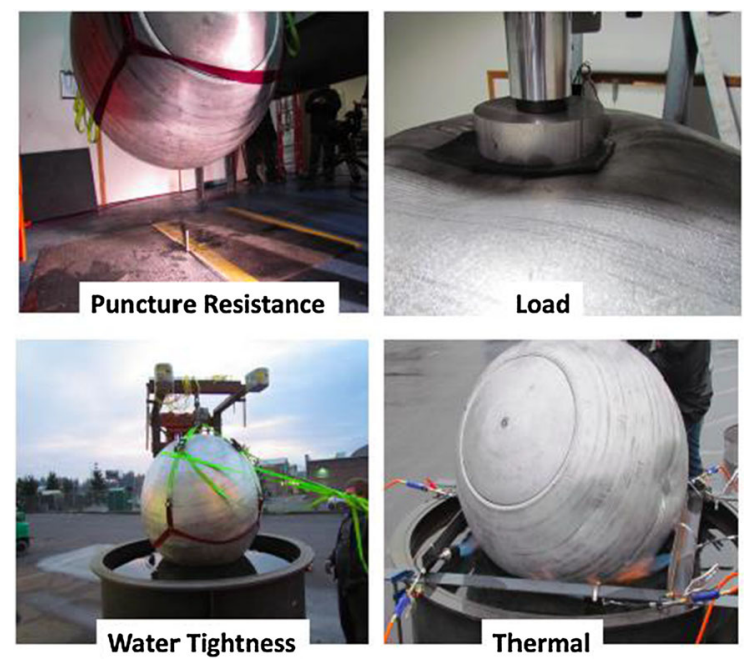

Figure 10

Laboratory testing of capsule for puncture resistance, loads, watertightness, and thermal effects. Photos by Survival Capsule

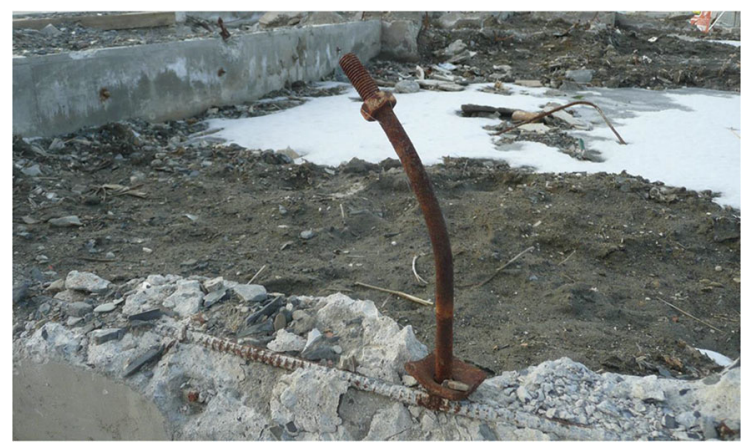

Figure 11

Remaining rebar after house is washed away during the 2011 Japanese tsunami near Sendai, Japan (Photo by E. Bernard)

people from extreme loads like being trapped between two automobiles.

c. Watertightness: since the capsule floats, it is critical that the entry door remain watertight after being exposed to a large load (i.e., two cars colliding into each other) or puncture.

d. Thermal: fires are a real hazard during a tsunami so any capsule must protect occupants from burning to death. According to Enomoto et al. (2019), "a comprehensive survey by the Japan Association for Fire Science and Engineering, a total of 159 tsunami-related fires occurred in the aftermath of the 2011 Tohoku-Oki earthquake. Of these, the specific origins of those fires (such as vehicles, electricity meters, and power panels) could be determined only in 56 cases, which means that, for the other 103 cases, the fire origins remain unknown."

Correlation between design and testing results verified that the capsule design was able to protect occupants from tsunami life threatening hazards (Sharpe et al., 2013).

After testing was completed the capsule was subjected to an extreme simulation of a tsunami by going over a $60 \mathrm{~m}$ waterfall (Fig. 12). The impact velocity of the capsule was $121 \mathrm{~km} / \mathrm{h}$ or 3 times the projected velocity of a tsunami. The capsule passed the extreme test. Different size capsules can hold 2,4, 6,8 , and 12 people, suitable for residences, small businesses, motels, apartments or schools.

A 2021 study of Vertical Evacuation Options for Ocean Shores, WA, (Freitag \& Gomez, 2021) estimated the cost of 11 structures to protect 5,300 people to be $\$ 56,471,694$ (or $\$ 10,655 /$ person). This estimate does NOT include the cost of the land required to site the structure. For comparison, a 12-person capsule estimated 2021 cost is $\$ 60,000$ (or $\$ 5000 /$ person) suitable for businesses, apartments, motels, and schools. A 4-person capsule estimated 2021 cost is $\$ 28,000$ (or $\$ 7000 /$ person) suitable for residences. Capsules do NOT require any dedicated land. The 4-person and 12-person capsule options are 34-53\% less expensive than the vertical evacuation option on a cost/person comparison. For the economics of vertical structure vs capsule, the main difference is the initial cost. To save the $1^{\text {st }}$ person using an average vertical evacuation structure for Ocean Shores is over $\$ 5.00 \mathrm{M}$, while using the capsule the cost to save the 1 st person is between $\$ 0.03$ $\$ 0.06 \mathrm{M}$. Maintenance costs for each $\$ 5 \mathrm{M}$ structure will range from (1-3\%/year or $\$ 50,000-\$ 150,000$ / year) while the cost to maintain a capsule is $\$ 30 /$ year (to replace the "O" ring for the watertight doors every 10 years). A community can gradually add capsules over time to spread out the costs, while providing immediate and expanding protection for its citizens. 
- Palouse Falls, USA $\quad-198 \mathrm{ft} .(60 \mathrm{~m})$

- Impact Velocity - $75 \mathrm{mph},(121 \mathrm{~km} / \mathrm{h})$

- Max Gross Weight $\quad-1000$ lbs. (454 kg)
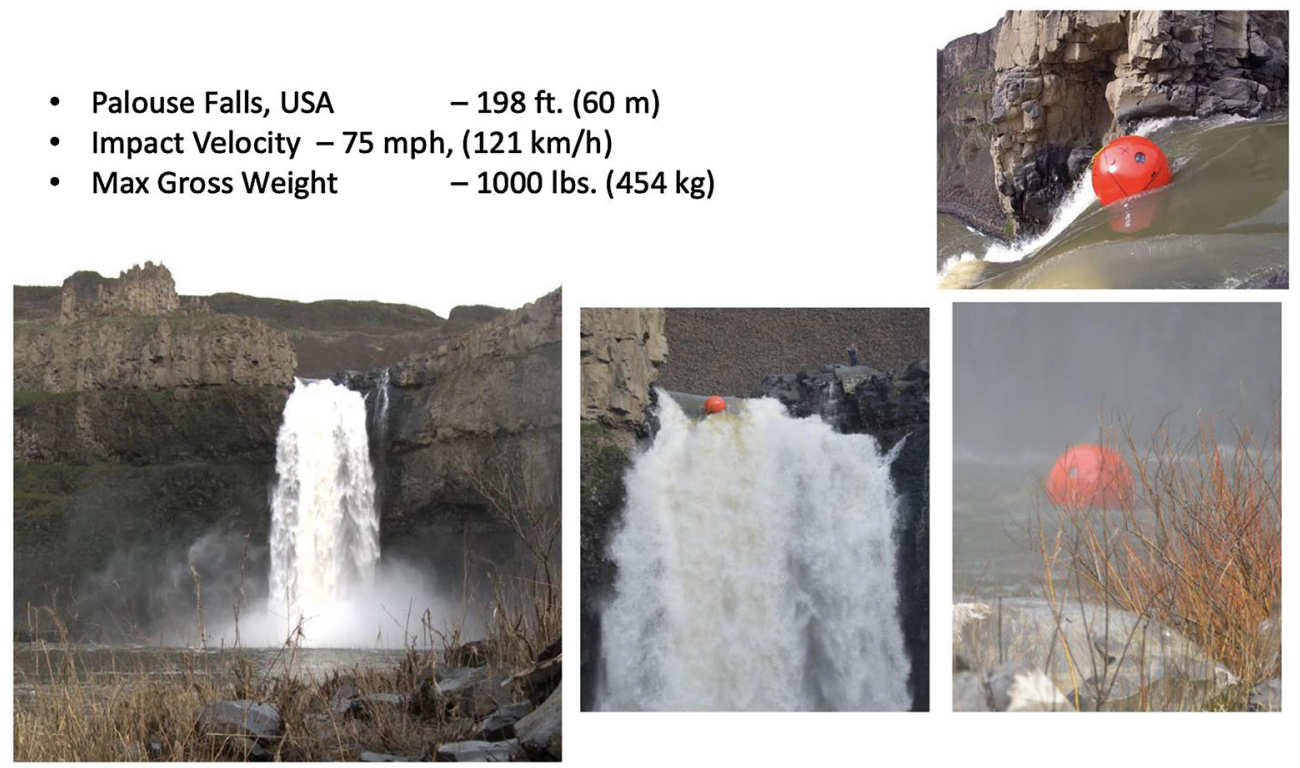

Figure 12

Testing Survival Capsule under extreme impact velocity by going over a $60 \mathrm{~m}$ waterfall with terminal velocity of $121 \mathrm{~km} / \mathrm{h}$. Photos by Survival Capsule

\section{Simulations of Capsule Trajectories During Tsunami Flooding}

One aspect of the floating Survival Capsule is where the capsule will be ultimately deposited. To address this important issue, a high-resolution tsunami flooding model of Newport, Oregon was used to simulate the trajectories of 20 capsules subjected to three different tsunami scenarios generated by hypothetical Cascadia Subduction Zone earthquakes.

To understand why this model was used, some context is required. Oregon State University (OSU) proposed to build a new facility next to its existing facility on the peninsula at South Beach, Newport, Oregon. Since the building site is within the tsunami inundation zone, OSU commissioned a study of the tsunami impact on the proposed facility in 2017. One aspect of the study was to determine if the NOAA, OSU and commercial ships, docked near the proposed facility, would pose a danger to the facility during a tsunami. Wei (2019) developed a sitespecific numerical model to determine the tsunami hazard using high-resolution grids to compute tsunami inundation depth and velocities at the study site (Fig. 13). The model used a combination of a depth- averaged shallow water model for offshore propagation and a Boussinesq-type model for onshore inundation. The numerical model was validated using the 2010 Chilean and 2011 Japanese tsunamis, which were recorded by the South Beach tide gauge. Comparison between the observed and modeled time series of tsunami amplitudes showed $90 \%$ agreement for amplitude and wave period (Wei, 2019). Wei and Zhou (2019) utilize the validated tsunami flooding model results to track the movement of large vessels in the vicinity of the building site to determine if these vessels would impact the building during the extreme tsunami scenarios (Fig. 14). The large vessels were assigned mass considering drag force, inertial force, ship grounding and mooring (Fig. 14a). No ship maneuvering is considered in these simulations.

Three Cascadia Subduction Zone scenarios, two deterministic scenarios, 2500 and 10,000 year recurrence earthquakes with activation of the splay fault proposed in Witter et al. (2011) and a 2500 year probabilistic scenario compliant with the new ASCE 7-16 standard, were used to simulate the trajectories of the moored ships. The simulation results from all three scenarios, including the 2500 year recurrence 


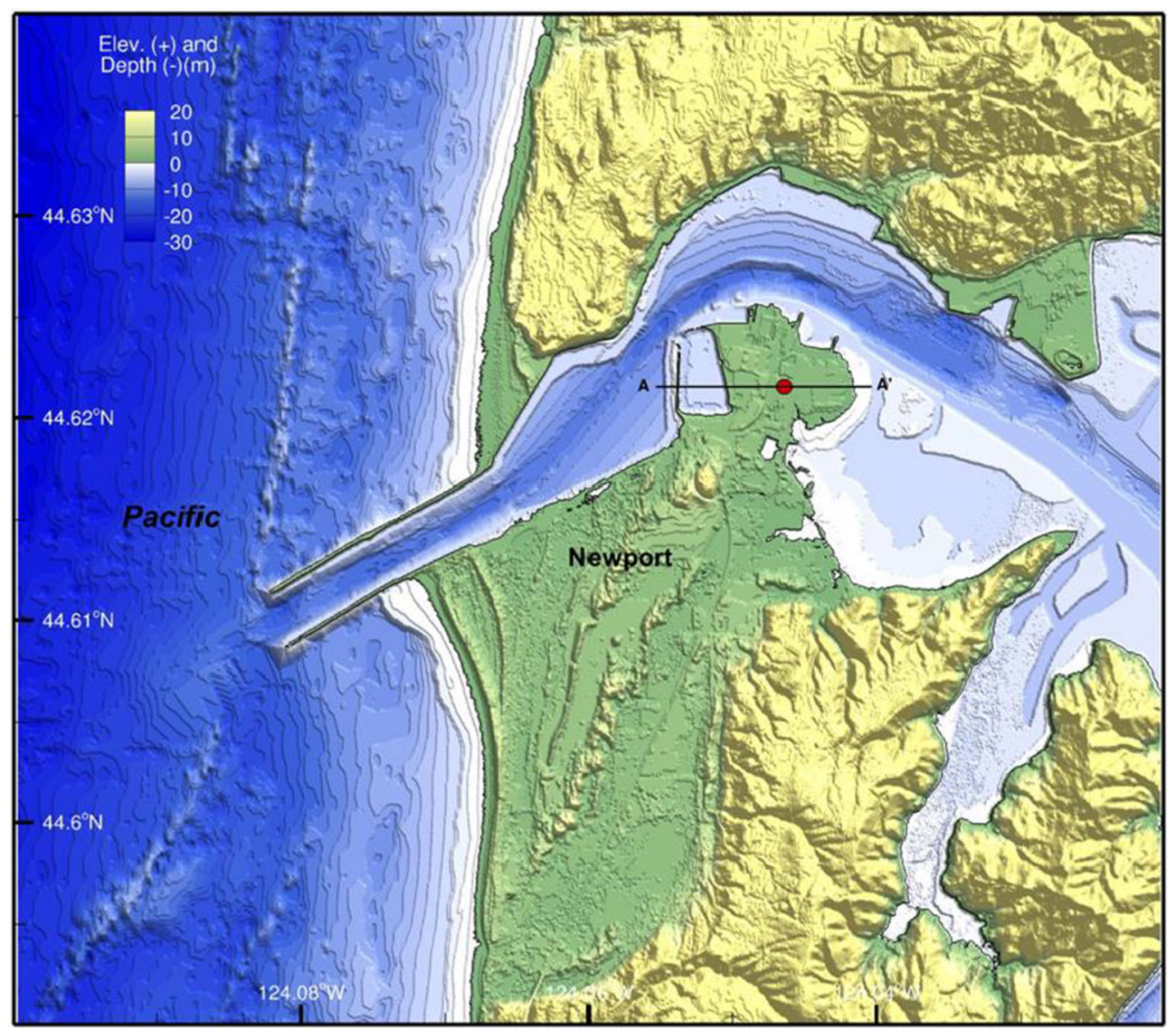

Figure 13

Bathymetry and topography of level-4 model grid where the red circle indicates the building site. (from Wei, 2019)

earthquake showed that none of the large vessels impacted on the building site (Fig. 14b). The OSU building, in operation since 2020, was awarded with the Grand Prize of 2021 Structural Engineers of Oregon (SEAO) Excellence in Structural Engineering Awards program.

Using the Wei model, twenty 2-m diameter survival capsules (with 4 occupants) with a mass of $454 \mathrm{~kg}$ and a draft of $0.5 \mathrm{~m}$ were placed in populated locations around Newport and South Beach (Fig. 15a). Note that these locations are not along the beaches because there are no residences or businesses located on the beaches. The results of 3 simulations: 2500 and 10,000 year recurrence tsunamis and of a 2500 year probabilistic tsunami are shown in Figs. 15b, 16 a and b, where all capsules shown in Fig. 15a are washed inland or into the bay. It is worth noting that for the 2500 and 10,000 year recurrence tsunamis, the water overflowing the South Beach highlands occurs only once when the largest first wave arrives at about $25 \mathrm{~min}$ into the event, and the capsule transportation was simulated up to $72 \mathrm{~min}$ after the earthquake (Figs. 15b and 16a). The 2500 year recurrence tsunami, however, causes the over-washing twice at about $30 \mathrm{~min}$ and $1 \mathrm{~h}$ and $50 \mathrm{~min}$ into the events, and the simulation for this scenario is, therefore, up to $130 \mathrm{~min}$ after the earthquake (Fig. 16b). If the ships and the capsules collided during a tsunami, the capsule would simply bounce off the ship. The speed of the capsule and vessel would be the same, so the impact on the capsule would not be damaging. Since the capsules are heavy with 4 occupants, they will probably be grounded when the tsunami waves recede. None of 


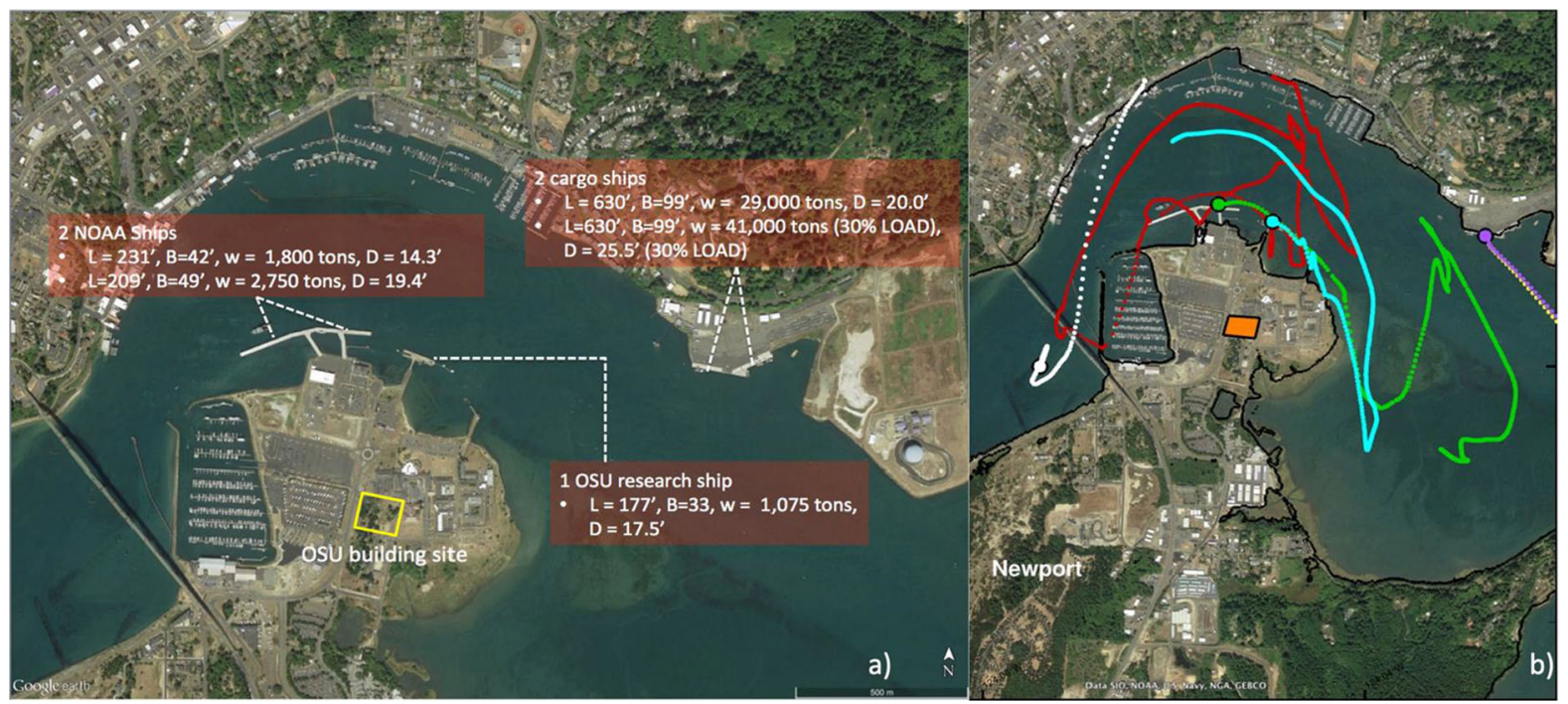

Figure 14

a Locations and main parameters of the ships to be considered in the debris impact study. The yellow rectangle is the OSU building site. L (length of vessel in feet), w (weight in tons), D (draft in feet) (b) simulated tracks of all moored ships for the 2500 year recurrence scenario. b red circles $=$ the track of ship NOAA 1 ; cyan circles $=$ track of ship NOAA 2 ; white circles $=$ track of a ship like NOAA 1 initially positioned in the channel without any mooring influence; green circles $=$ track of OSU; yellow circles and purple circles $=$ track of Cargo 2 .

(from Wei and Zhou (2019))
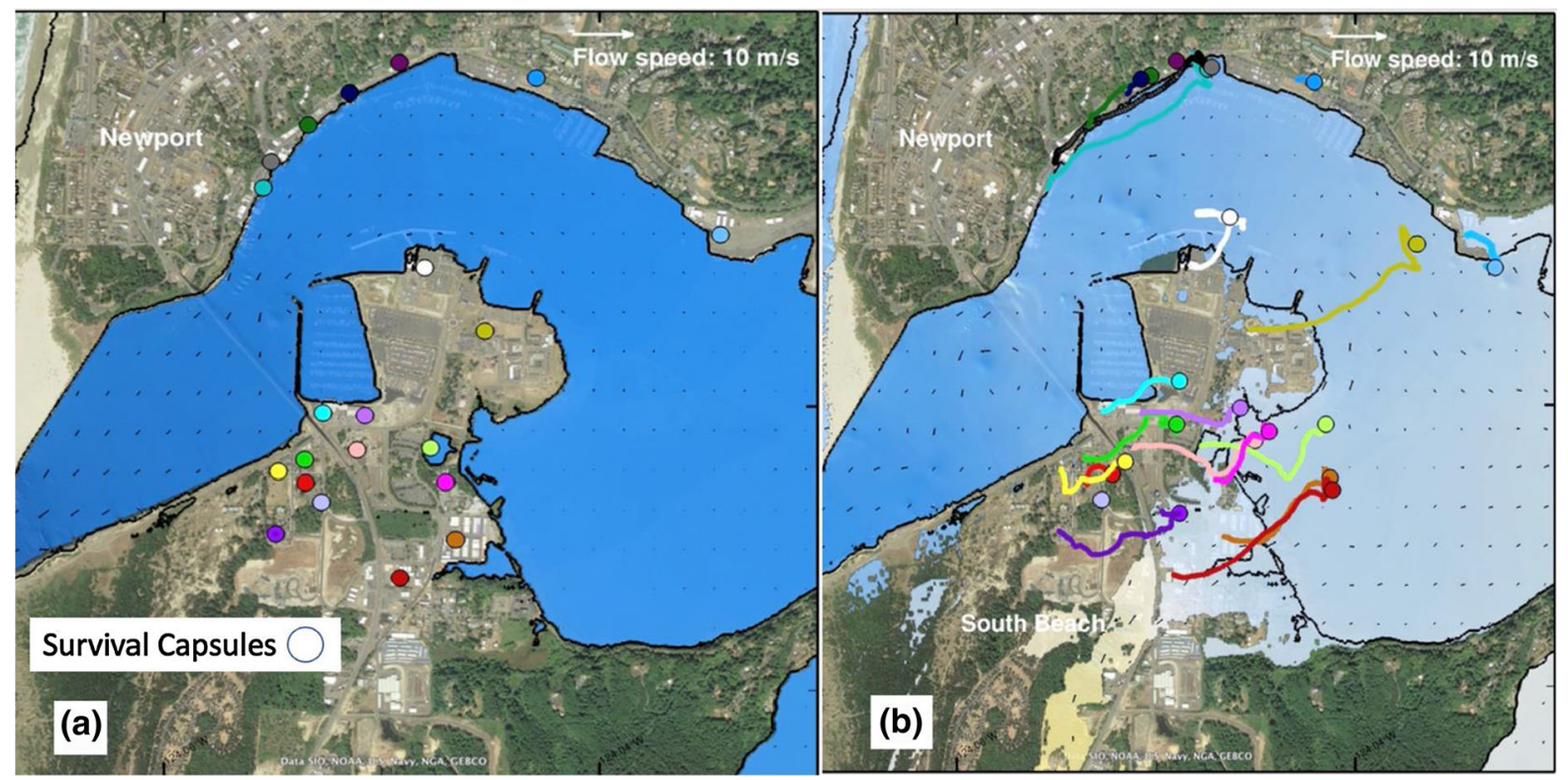

Figure 15

a Initial position of 20 capsules in and around Newport, Oregon and b final positions of 20 capsules subjected to 72 min simulation of the 2500 year recurrence tsunami 

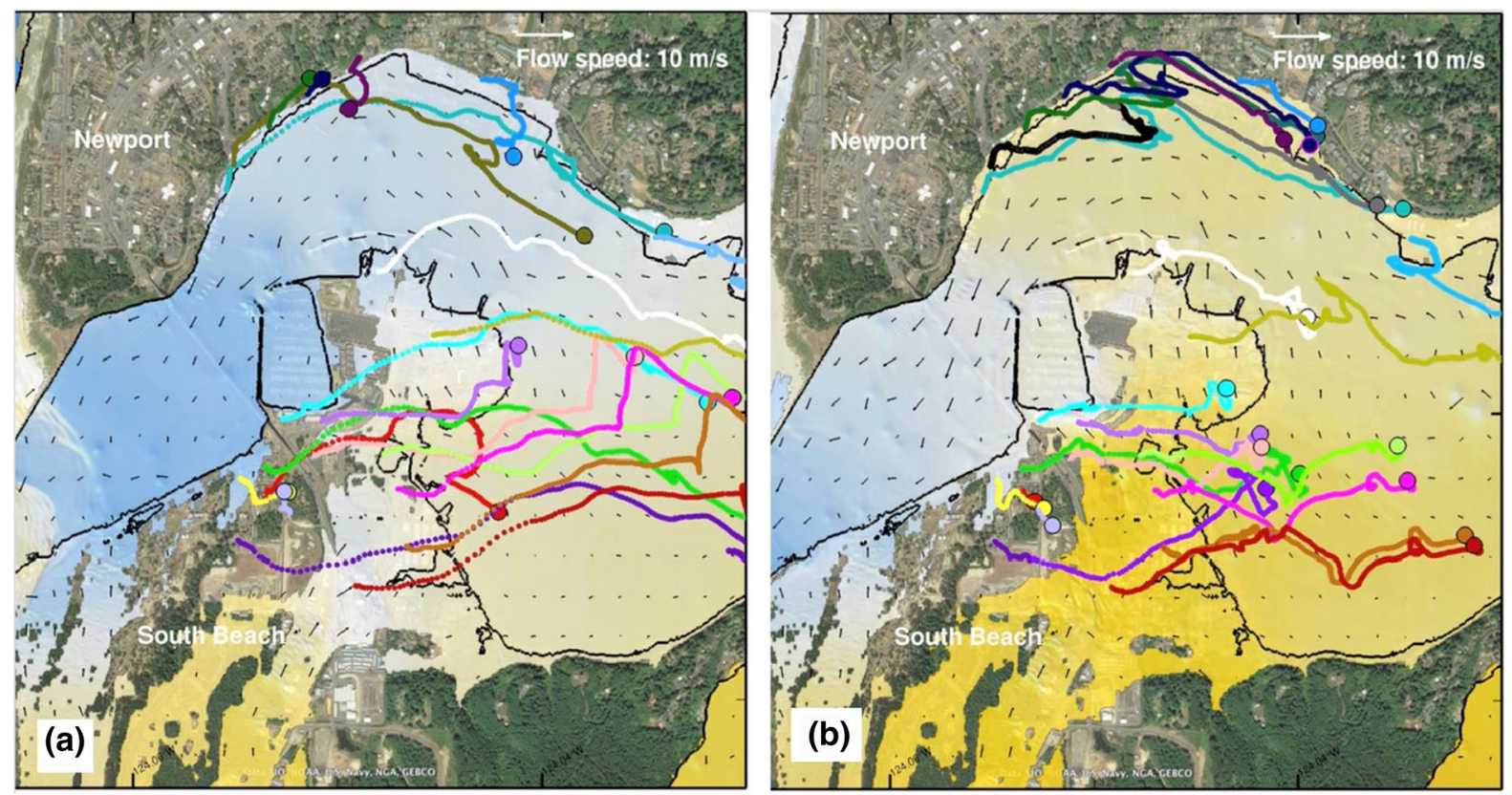

Figure 16

Final positions of 20 capsules subjected to (a) 72 min simulation of the 10,000 year recurrence tsunami and b 130 min simulation of a 2500 year probabilistic tsunami

the capsules were washed out to sea. However, this example is site specific for Newport, Oregon. Each tsunami-threatened community will have a different set of tsunami dynamics.

\section{Conclusions}

This study introduces a third option for saving lives during a tsunami-shelter-in-place. This option can be used in tsunami preparedness plans to complement existing horizontal and vertical evacuation procedures for those living and working within tsunami hazard zones. A coastal community could use the three options in combination tailored for their situation. For example, a community may use these 3 options as follows:

Horizontal evacuation with shelters would be used where high ground is available to people who can walk to high ground before the estimated time of tsunami arrival. Once they are safely evacuated, shelters are available for shelter, food, and water. Individuals must prepare by creating a "go bag", which contains individual needs such as glasses, medications, valuables, and other personal items, that can be quickly grabbed and carried by the evacuee. Pets are generally not allowed in the shelters.

Vertical evacuation shelter would be used in high density populated areas where horizontal evacuation is not possible. It is for people who can walk to a vertical structure and climb the 4-5 flights of stairs before the estimated time of tsunami arrival. Such areas may include apartments, schools, businesses, motels, and other high-occupancy structures. Some vertical evacuation structures have food and water available. Individuals must prepare by creating a "go bag", which contains individual needs such as glasses, medications, valuables, and other personal items, that can be quickly grabbed and carried by the evacuee. Pets are generally not allowed in these shelters.

Shelter-in-place would be used where horizontal or vertical evacuation is not possible or by people who are unwilling to evacuate to shelters. Shelter-inplace structures, which require immediate accessibility and can protect the occupants from drowning, 
being crushed by floating objects, being burned to death, being exposed to cold water, ingesting toxic sand and silt and exposure to contagious diseases (Fig. 8) can save lives. People unwilling to evacuate may fear safety and contagious diseases (or pandemic) found in congested horizontal and vertical shelters or they may want to save their pets. Shelterin place structures may be a cost-effective alternative for some vertical evacuation structures, especially in low population density areas such as residential housing developments or nursing homes. Using Ocean Shores estimates for vertical evacuation tower costs, 4 and 12-person Survival Capsules are from 34-53\% less expensive per person protected. Individuals must prepare by placing personal needs such as food, water, glasses, medications, valuables, sturdy waterproof boots, N95 face masks, GPS tracking device and other personal items in the capsule. Pets are allowed in shelters-in-place capsules.

If a tsunami threatened community uses all three options in a well exercised tsunami preparedness program, it IS possible to have zero casualties from the next tsunami.

\section{Acknowledgements}

This research was supported by Survival Capsule, LLC and the author acknowledges the contributions of photographs and fruitful discussions with Survival Capsule President, Julian Sharpe. The author gratefully acknowledges the contributions of Yong Wei, who provided the results of numerical modeling experiments simulating the tsunami flooding trajectories of 20 capsules in Newport, Oregon generated by three different hypothetical Cascadia Subduction Zone earthquakes. He also produced the graphics for Figures 15 and 16. The author also gratefully acknowledges the support of the late President Iwao Iwama, Toho Mercantile Co, LTD, for arranging and financing the author's visit to Kuroshio Town. Mr. Iwama's concern for the safety of Japanese citizens from the next tsunami inspired this research. He also acknowledges the contributions of the City of Kuroshio Town, including Mayor Katsuya Oonishi and Emergency Manager Toshirou Matsumoto, who provided a presentation of the city's goal to achieve zero casualties from the next tsunami and an extensive tour of the mitigation facilities during the author's visit to this beautiful coastal city. The author also acknowledges the insightful discussions with Susan Conniry of the Ocean Shores City Council. The author also acknowledges the extremely useful suggestions of two reviewers.

E.B. is Vice-President for Research and part owner of Survival Capsule, LLC.

Open Access This article is licensed under a Creative Commons Attribution 4.0 International License, which permits use, sharing, adaptation, distribution and reproduction in any medium or format, as long as you give appropriate credit to the original author(s) and the source, provide a link to the Creative Commons licence, and indicate if changes were made. The images or other third party material in this article are included in the article's Creative Commons licence, unless indicated otherwise in a credit line to the material. If material is not included in the article's Creative Commons licence and your intended use is not permitted by statutory regulation or exceeds the permitted use, you will need to obtain permission directly from the copyright holder. To view a copy of this licence, visit http://creativecommons.org/licenses/by/4. $0 \%$

Publisher's Note Springer Nature remains neutral with regard to jurisdictional claims in published maps and institutional affiliations.

\section{REFERENCES}

Álvarez, G., Quiroz, M., León, J., \& Cienfuegos, R. (2018). Identification and classification of urban micro-vulnerabilities in tsunami evacuation routes for the city of Iquique, Chile. Natural Hazards and Earth Systems Sciences, 18, 2027-2039.

Birkmann, J., Baumet, N., \& Setiadi, N.J. (2008). Socio-economic vulnerability assessment at the local level in context of tsunami early warning and evacuation planning in the City of Padang, West Sumatra. In: Conference: Paper for International Conference on Tsunami Warning (ICTW), Bali, Indonesia, November 12-14, 2008

CDMC - Central Disaster Management Council: Working group report on mega-thrust earthquake models for the Nankai Trough, Japan, Cabinet Office of the Japanese Government, Tokyo, available at: http://www.bousai.go.jp/jishin/nankai/taisaku/pdf/ 20120829_2nd_report01.pdf, last access: December 2012.

Cyranoski, D. (2011). Japan's tsunami warning system retreats. Nature. https://doi.org/10.1038/news.2011.477

Davies, G. J., Griffin, F., Løvholt, S., Glimsdal, C., Harbitz, H. K., Thio, S., Lorito, R., Basili, J., Selva, E. G., \& Baptista, M. A. (2017). A global probabilistic tsunami hazard assessment from earthquake sources Geological Society. London, Special Publications, 456, 219-244. https://doi.org/10.1144/SP456.5 
Doocy, S., Rofi, A., Moodie, C., Spring, E., Bradley, S., Burnham, G., \& Robinson, C. (2007). Tsunami mortality in Aceh Province, Indonesia. Bulletin of the World Health Organization, 85(4), 273-278. https://doi.org/10.2471/blt.06.033308

Enomoto, Y., Yamabe, T., Sugiura, S., \& Kondo, H. (2019). Possible mechanism for the tsunami-related fires that occurred at Aonae Harbor on Okushiri Island in the 1993 Hokkaido NanseiOki earthquake. Geosciences, 9(6), 253. https://doi.org/10.3390/ geosciences 9060253

Frankenberg, E., Gillespie, T., Preston, S., Sikoki, B., \& Thomas, D. (2011). Mortality, the family and the Indian Ocean Tsunami. The Economic Journal, 121(554), 162-182.

Fraser, S., Leonard, G. S., Hitomi, M., \& Matsuo, I. (2012). Tsunami vertical evacuation buildings-lessons for International Preparedness Following the 2011 Great East Japan tsunami. Journal of Disaster Research, 7, 446-457.

Freitag, B., \& Gomez, J. (2021). Tsunami vertical evacuation options, Grays Harbor County (Vol. 2, p. 432). Institute for Hazards Mitigation Planning and Research, Department of Urban Design and Planning, University of Washington.

Hewitt, K. (1983). The idea of calamity in a technocratic age. In K. Hewitt (Ed.), Interpret (pp. 3-32). Calam. Allen and Unwin.

Inoue, Y., Fujino, Y., Onodera, M., Kikuchi, S., Shozushima, T., Ogino, N., Mori, K., Oikawa, H., Koeda, Y., Ueda, H., Takahashi, T., Terui, K., Nakadate, T., Aoki, H., \& Endo, S. (2012). Tsunami lung. Journal of Anesthesia, 26(2), 246-324. https://doi. org/10.1007/s00540-011-1273-6

IOC, 2021 http://www.ioc-tsunami.org/index.php?option=com content $\&$ view $=$ article $\&$ id $=458$ : guidelines-covid $19 \&$ catid $=$ 20\&lang=en\&Itemid $=68$

Kitagawa, K. (2019). Co-constructing a narrative of 'Never Give Up' in preparing for a mega-tsunami: an exemplar of 'All-OfSociety Engagement'? Geosciences, 9, 486. https://doi.org/10. 3390/geosciences9120486

Koshimura, S., \& Shuto, N. (2015). Response to the 2011 Great East Japan Earthquake and tsunami disaster. Philosophical Transactions of the Royal Society a: Mathematical, Physical and Engineering Sciences, 373(2053), 20140373.

Mas, E., Koshimura, S., Imamura, F., Suppasri, A., Muhari, A., \& Adriano, B. (2015). Recent advances in agent-based tsunami evacuation simulations: case studies in Indonesia, Thailand, Japan and Peru. Pure and Applied Geophysics, 172, 3409-3424.

McCaughey, J. M., Mundir, I., Daly, P., Mahdi, S., \& Patt, A. (2017). Trust and distrust of tsunami vertical evacuation buildings: extending protection motivation theory to examine choices under social influence. International Journal of Disaster Risk Reduction, 24, 462-473.

Merkens, J.-L., Reimann, L., Hinkel, J., \& Vafeidi, A. T. (2016). Gridded population projections for the coastal zone under the shared socioeconomic pathways. Global and Planetary Change, 145, 57-66.

Ochi, S., Murray, V., \& Hodgson, S. (2013). The Great East Japan earthquake disaster: a compilation of published literature on health needs and relief activities, March 2011-September 2012. PLOS Currents Disasters,. https://doi.org/10.1371/currents.dis. 771beae7d8f41c31cd91e765678c005d Edition 1.

Osso, F., \& Dominey-Howes, D. (2010). Public assessment of the usefulness of "draft" tsunami evacuation maps from Sydney, Australia-implications for the establishment of formal evacuation plans. Natural Hazards and Earth Systems Sciences, 10, 1739-1750.

Seto, S., Imamuara, F., \& Suppasri, A. (2019). Challenge to build the science of human survival from disaster starting from analysis for the 2011 Tohoku tsunami. Journal of Disaster Research, 14(9), 1323-1327.

Sharpe, J., Acklen, A., \& Hill, S. (2013). Tsunami survival capsule design and development program utilizing MSC software to support analytical correlation against test results. In: MSC Technical Conference, Los Angeles, CA.

Suzuki, M., Uwano, C., Ohrui, T., Ebihara, T., Yamasaki, M., \& Asamura, T. (2011). Shelter-acquired pneumonia after a catastrophic earthquake in Japan. Journal of the American Geriatrics Society, 59(10), 1968-1970.

Wei, Y. (2019). Site-specific modeling of debris tracking for the OSU marine science building at newport, OR (p. 17). YGH Architecture Technical Report.

Wei, Y., \& Zhou, H. (2019). Tsunami inundation modeling for the OSU marine studies initiative building (p. 39). YGH Architecture Technical Report.

Witter, R. C., Zhang, Y., Wang, K., Priest, G. R., Goldfinger, C., Stimely, L. L., English, J. T., \& Ferro, P. A. (2011). Simulating tsunami inundation at Bandon, Coos County, Oregon, using hypothetical Cascadia and Alaska earthquake scenarios (p. 57). DOGAMI Special Paper 43.

Wood, N., Jones, J., Schelling, J., \& Schmidtlein, M. (2014). Tsunami vertical-evacuation planning in the U.S. Pacific Northwest as a geospatial, multi-criteria decision problem. International Journal of Disaster Risk Reduction, 9, 68-83. https://doi.org/10.1016/j.ijdrr.2014.04.009 